\title{
ANALISIS MODEL PERAMALAN STATUS KREDIT KENDARAAN BERMOTOR PADA ASTRA CREDIT COMPANIES (ACC) CABANG X PERIODE 2011
}

\author{
Tomy G. Soemapradja; Prycillia Susanto \\ Jurusan Manajemen, Fakultas Ekonomi dan Komunikasi, BINUS University \\ Jln. K.H. Syahdan No. 9, Palmerah, Jakarta Barat 11480
}

\begin{abstract}
In order to increasing revenue, credit and financial institution, especially, automotive financing, gave lower interest rate. This, of course, will impact to the costumer with higher opportunity to have their dream which facilitated by those institutions. Despites to all economic risks and sales targets, credit and financial institutions have to empower their credit monitoring to anticipate earlier of credit defaults. Inspired by Altman's research in 1968, about predicting bankruptcy of US companies, this research has purpose to determine which variable that significantly to the car loan status at Astra Credit Companies (ACC), and further continue to arrange prediction model of loan status and measure it's accuracy level.. The statistic test shows there are 2 independent variables affect to dependent variable significantly, where model's accuracy level achieves $100 \%$.
\end{abstract}

Keywords: prediction, credit status, automotive, Astra Credit Companies (ACC)

\begin{abstract}
ABSTRAK
Lembaga pembiayaan kredit, khususnya kredit konsumtif kendaraan bermotor, berusaha meningkatkan pendapatannya dengan penurunan tingkat bunga kreditnya. Hal ini tentu berimbas pada meningkatnya peluang calon debitur untuk memiliki kendaraan bermotor dengan fasilitas kredit dari lembaga tersebut. Terlepas dari segala risiko ekonomi dan pencapaian target penjualan, fungsi credit monitoring perlu ditingkatkan agar lembaga pembiayaan dapat mengidentifikasi dan melakukan langkah antisipatif lebih awal guna menurunkan risiko kredit bermasalah. Terinspirasi dari publikasi penelitian Altman di tahun 1968, tentang peramalan tingkat kebangkrutan perusahaan di AS, penelitian ini bertujuan untuk menentukan variabel-variabel manakah yang signifikan terhadap status kredit kendaraan bermotor di Astra Credit Companies (ACC), yang dilanjutkan pada pengembangan model peramalan status kredit dan tingkat akurasinya. Hasil pengujian statistik menunjukkan bahwa terdapat 2 variabel bebas yang signifikan terhadap variabel terikat dengan tingkat akurasi $100 \%$.
\end{abstract}

Kata kunci: prediksi, status kredit, kendaraan, Astra Credit Companies (ACC) 


\section{PENDAHULUAN}

Beberapa perusahaan pembiayaan kredit kendaraan bermotor telah menurunkan tingkat bunga kredit pembiayaan kendaraan bermotor agar lebih kompetitif dibandingkan dengan pesaingnya, bahkan ada yang memberikan program bunga rendah sebesar $3-6 \%$ dari rata-rata bunga kredit pembiayaan kendaraan bermotor yang mencapai $25-30 \%$. Sisi positif penurunan tingkat bunga kredit tersebut tentu memperbesar peluang konsumen dengan kemampuan finansial yang terbatas untuk memiliki kendaraan bermotor, serta lebih memberdayakan dana yang dialokasikan untuk pembiayaan. Sisi lain yang layak dipertimbangkan, seringkali demi mengejar target penjualan, dalam jangka panjang, banyak kredit yang bermasalah, macet sebelum kredit tersebut lunas.

Dalam publikasi penelitian Altman (1966) menganalisis variabel-variabel bebas berupa rasio keuangan untuk membangun model peramalan tingkat kebangkrutan perusahan di AS, yang kemudian model ini dikembangkan lebih lanjut ke bidang keuangan—perbankan, bahkan telah diterapkan di Indonesia, yang dikenal dengan analisis tingkat kesehatan bank: CAMELS, menggunakan data kualitatif dan kuantitatif. Terinsiprasi dari penelitian di atas, yang dihubungkan dengan populasi kendaraan bermotor Indonesia yang terbanyak di ASEAN (Tempo, 2011) dengan penjualan sepanjang tahun 2011 sebesar 880.000 unit mobil (Kompas, 2011), dimana 70 - 80\% pembelian mobil menggunakan fasilitas kredit (Executive Vice President PT. Astra Honda Motor Johannes Loman, Antara, 2011), padahal rata-rata tingkat bunga kredit perbankan Indonesia justru paling tinggi di ASEAN (finance.detik.com), yang berdampak pada tingkat bunga kredit kendaraan bermotor di Indonesia. Hal yang paling dikhawatirkan adalah tingginya tingkat bunga tersebut tentu berdampak pada kemampuan angsuran para pembeli kendaraan bermotor secara kredit dan berujung pada pelunasannya, sehingga semua perusahaan yang bergerak di bidang pembiayaan kendaraan bermotor perlu melakukan langkah antisipatif berupa upaya monitoring dengan kriteria kuantitatif yang dapat memberikan peringatan dini (early warning) atas dari data-data para debiturnya.

Astra Credit Companies (ACC) merupakan salah satu anak perusahaan PT. Astra International, Tbk, salah satu holding company terbesar yang bergerak di bidang otomotif di Indonesia. ACC khusus bergerak di bidang jasa pembiayaan kendaraan bermotor, baik kendaraan baru maupun bekas. Perusahaan ini telah mengoperasikan 52 kantor cabang dan outlet layanan di 39 kota besar di Indonesia. Selain produk pembiayaan, tersedia juga berbagai bentuk usaha kemitraan dengan lebih dari 2.000 dealer otomotif di seluruh Indonesia. Rasio kredit macet perusahaan ini tahun 2010 mencapai 0,89\%, sementara kredit macet industri kendaraan bermotor mencapai 2-5\% (www.oto.detik.com). Walaupun dapat dikatakan relatif rendah, risiko kredit macet tetap perlu diantisipasi secara serius, baik saat melakukan analisis kelayakan debitur, terutama sesudah persetujuan kredit sampai dengan pelunasan kredit di akhir periode kesepakatan.

Tujuan penelitian ini yaitu:(1) menentukan prioritas faktor-faktor penyebab kredit bermasalah; (2) untuk menentukan variabel-variabel kredit kendaraan bermotor manakah yang berpengaruh secara signifikan terhadap status kredit tersebut pada Astra Credit Companies; (3) untuk menentukan model peramalan status kredit kendaraan bermotor pada Astra Credit Companies; dan (4) untuk menentukan tingkat akurasi model peramalan status kredit kendaraan bermotor pada Astra Credit Companies.

Berdasarkan tujuan penelitian di atas, maka manfaat penelitian adalah: (1) meningkatkan proses monitoring kredit sebagai sistem peringatan dini sebelum kredit kendaraan bermotor menjadi kredit bermasalah dengan tambahan analisis kuantitatif yang teruji secara statistik; dan (2) meningkatkan kualitas analisis kuantitatif yang dapat dilanjutkan oleh penelitian berikutnya atau strategi pengembangan produk kredit kendaraan bermotor yang lebih menguntungkan perusahaan. 


\section{Tinjauan Pustaka}

Berdasarkan tujuannya, kredit dapat dibedakan menjadi kredit konsumtif dan kredit produktif, kredit perdagangan (Judiseno, 2002). Kredit konsumtif bertujuan untuk memperlancar kegiatan konsumtif, misalnya pembelian rumah (KPR), pembelian kendaraan bermotor dan kredit konsumtif lainnya. Kredit produktif bertujuan untuk memperlancar proses operasional atau produksi, misal kredit investasi aset jangka panjang. Kredit perdangan bertujuan untuk memperlancar kegiatan perdagangan, misalnya kredit modal kerja.

Kredit konsumtif banyak diminati oleh masyarakat, terutama yang terbesar adalah kredit kendaraan bermotor (Judiseno, 2002). Pihak-pihak yang terkait dengan proses kredit pembelian kendaraan bermotor adalah dealer, lembaga bank maupun lembaga pembiayaan bukan bank, calon pembeli dan asuransi, bersifat optional (Judiseno, 2002). Sebagian besar pasar mobil bekas tidak dijual langsung oleh seseorang ke orang lain, karena keterbatasan informasi historikal tentang mobil bekas tersebut sehingga dimanfaatkan oleh kerjasama antara dealer dan bank atau lembaga pembiayaan bukan bank (Mishkin, 2008).

Terjadinya wanprestasi adalah awal mula terjadinya kredit bermasalah—bahkan menjadi kredit macet. Prof. R. Subekti, SH menyatakan penyebab terjadinya wanprestasi adalah: (1) tidak melakukan apa yang disanggupi akan dilakukannya; (2) melaksanakan apa yang dijanjikannya tetapi tidak bagaimana yang dijanjikan; (3) melakukan yang dijanjikan tetapi terlambat; dan (4) melakukan sesuatu yang menurut perjanjian tidak boleh dilakukannya (Haryani, 2010).

Berdasarkan ketentuan Bank Indonesia, penggolongan status kredit didasarkan pada kolektibilitas kredit, yaitu "keadaan pembayaran pokok atau angsuran pokok dan bunga kredit oleh nasabah serta tingkat kemungkinan diterimanya kembali dana yang ditanamkan dalam surat-surat berharga atau penanaman lainnya.” Kolektibilitas kredit digolongkan menjadi 5 (lima), yaitu: Lancar, Dalam Perhatian Khusus, Kurang Lancar, Diragukan dan Macet (Bank Indonesia).

Credit Risk Mitigation adalah salah satu metode untuk mengelola risiko kredit untuk mengurangi peluang terjadinya kredit bermasalah, yaitu grading models for individual loans, loan portfolio management, securitization, collateral, cashflow monitoring dan recovery management (Hardanto, 2006). Secara kronologis, Credit Risk Mitigation menggunakan sebuah model kuantitatif, dimulai dari sebelum dan sesudah pengajuan kredit, dari faktor analisis sampai credit monitoring untuk mengurangi peluang terjadinya kredit bermasalah.

Penelitian Altman (1968) tentang formula Z-Score yang memprediksi kebangkrutan perusahaan di AS berdasarkan rasio keuangan beberapa tahun sebelum terjadinya kebangkrutan. Konsep penelitian Altman dikembangkan lebih lanjut dalam menentukan peringkat surat hutang perusahaan (Altman, 2002) serta salah satunya juga diaplikasikan dalam manajemen modal kerja, khususnya peramalan piutang, seperti penelitian yang dilakukan oleh Krishnamurthy (2011).

Altman (1968) menggunakan 66 data perusahaan, dimana 33 data rasio keuangan berasal dari perusahaan yang sehat dan 33 data berasal dari perusahaan yang bangkrut-di sinilah awal data "pembedaan” sebagai dasar analisis diskriminan, dimana semua data berasal dari 1-5 tahun sebelum perusahaan tersebut bangkrut atau bertahan. Tingkat akurasi model prediksi kebangkrutan Altman (1968) mencapai 36-95\%, di mana semakin dekat tahun yang digunakan dengan kejadian bangkrut maka semakin tinggi tingkat akurasinya.

Dalam analisis regresi berganda, variabel terikat membutuhkan data berskala interval atau rasio. Dalam prakteknya, analisis diskriminan dengan regresi berganda dapat menggunakan data berskala nominal (Rubin, 2010). Jika direlevansikan dengan penelitian Altman (1968), maka data 
variabel terikat yang berasal dari dari sampel perusahaan yang bertahan (survive) adalah 1 (satu), sedangkan data yang berasal dari sampel perusahaan bangkrut adalah 0 (nol). Tingkat akurasi analisis diskriminan dengan regresi berganda yang variabel bebas berskala data interval atau rasio, serta variabel terikat berskala data nominal justru lebih baik, karena kualitas data variabel bebas lebih tinggi daripada variabel terikatnya (Rubin, 2010). Analisis statistik regresi berganda dapat dilakukan dengan langkah lebih sederhana tetapi hasil tidak jauh beda dengan Ms Excel (Harmon, 2011), sedangkan untuk menguji asumsi klasik dapat menggunakan SPSS (Leech, 2005)

\section{METODE}

Jenis data penelitian ini adalah data sekunder yang berasal dari data perusahaan Astra Credit Companies. Pengumpulan sampel termasuk purposive sampling, karena ke-40 dipilih dengan kriteria, yaitu 20 sampel yang berasal dari kredit tidak bermasalah, serta 20 sampel sisanya berasal dari kredit yang bermasalah (macet). Analisis data menggunakan uji asumsi klasik dan analisis statistik multi regresi pada tingkat signifikansi tertentu. Alat pendukung berupa Ms Excel dengan tambahan fungsi add-ins berupa Analysis ToolPak.

\section{HASIL DAN PEMBAHASAN}

Hasil penelitian secara keseluruhan menunjukkan bahwa data harga mobil on the road (OTR) memiliki kisaran data Rp 42-420 juta yang berasal dari mobil tahun (THN) 1995-2011. Uang muka kredit pembelian mobil tersebut berkisar antara Rp 8,4-133,5 juta, atau secara prosentase berkisar antara 10-57\% dari harga OTR (tergantung periode kredit dan pengajuan DP oleh calon nasabah ACC). Besarnya angsuran berkisar antara Rp 1,4-10,1 juta, dalam periode pelunasan 3-3,5 tahun dengan tingkat bunga 5-16,7\% per tahun. Data selengkapnya dapat dilihat pada Tabel 1 berikut.

Tabel 1 Deskripsi statistik faktor-faktor debitur

\begin{tabular}{lrrrrrrr}
\hline & OTR & DP & ANGS & DEN & FRE & BNG & THN \\
\hline Mean & 155.3338 & 31.2935 & 4.4709 & 5.118 & 1.2 & 32.13264 & 2006 \\
Standard Error & 11.02549 & 3.633846 & 0.3118 & 1.20147 & 0.268424 & 2.467311 & 0.72 \\
Median & 150.55 & 26.9018 & 4.2055 & 1.59075 & 0.5 & 30.74705 & 2007 \\
Mode & 205 & 41 & 6 & 0 & 0 & 46.014 & 2009 \\
Standard Deviation & 69.73132 & 22.98246 & 1.9722 & 7.59879 & 1.697661 & 15.60464 & 4.553 \\
Sample Variance & 4862.458 & 528.1935 & 3.8896 & 57.7416 & 2.882051 & 243.5049 & 20.73 \\
Kurtosis & 4.356999 & 9.686012 & 0.5976 & 11.4723 & 1.370643 & 0.212655 & 1.017 \\
Skewness & 1.383784 & 2.655753 & 0.7302 & 2.83443 & 1.523863 & 0.793901 & -1.39 \\
Range & 378 & 125.1905 & 8.755 & 40.644 & 6 & 61.976 & 16 \\
Minimum & 42 & 8.4 & 1.406 & 0 & 0 & 10.395 & 1995 \\
Maximum & 420 & 133.5905 & 10.161 & 40.644 & 6 & 72.371 & 2011 \\
Sum & 6213.35 & 1251.74 & 178.84 & 204.72 & 48 & 1285.305 & 80232 \\
Count & 40 & 40 & 40 & 40 & 40 & 40 & 40 \\
\hline
\end{tabular}


Untuk merinci perbedaan, maka data-data dari tabel sebelumnya diurai menjadi dua deskrispsi seperti pada Tabel 2.

Tabel 2 Deskripsi faktor-faktor debitur berdasarkan kriteria Lunas dan Macet

\begin{tabular}{lrrrrrrr}
\multicolumn{7}{l}{ Deskripsi Kredit Tidak Bermasalah (Lunas) } \\
\hline \multicolumn{1}{c}{ OTR } & \multicolumn{1}{c}{ DP } & ANGS & DEN & FRE & \multicolumn{1}{l}{ BNG } & \multicolumn{1}{c}{ THN } \\
\hline Mean & 143.7 & 30.5 & 4.0 & 0.1 & - & 24.3 & 2005 \\
Range & 238.8 & 73.3 & 6.6 & 0.5 & - & 40.1 & 13 \\
Min. & 59.3 & 12.0 & 1.8 & - & - & 10.4 & 1995 \\
Max. & 298.0 & 85.3 & 8.4 & 0.5 & - & 50.5 & 2008 \\
Count & 20.0 & 20.0 & 20.0 & 20.0 & 20.0 & 20.0 & 20 \\
\hline
\end{tabular}

Deskripsi Kredit Bermasalah (Macet)

\begin{tabular}{lrrrrrrr}
\hline & \multicolumn{1}{c}{ OTR } & \multicolumn{1}{c}{ DP } & \multicolumn{1}{c}{ ANGS } & \multicolumn{1}{c}{ DEN } & \multicolumn{1}{l}{ FRE } & \multicolumn{1}{c}{$B N G$} & THN \\
\hline Mean & 167.0 & 32.1 & 5.0 & 10.2 & 2.4 & 39.9 & 2007 \\
Range & 378.0 & 125.2 & 8.8 & 37.9 & 5.0 & 57.0 & 16 \\
Min. & 42.0 & 8.4 & 1.4 & 2.7 & 1.0 & 15.4 & 1995 \\
Max. & 420.0 & 133.6 & 10.2 & 40.6 & 6.0 & 72.4 & 2011 \\
Count & 20.0 & 20.0 & 20.0 & 20.0 & 20.0 & 20.0 & 20 \\
\hline
\end{tabular}

Harga mobil on the road (OTR) kredit yang lunas secara rata-rata ternyata justru lebih rendah daripada harga mobil OTR kredit yang bermasalah, jika dihubungkan dengan tahun pembuatan mobil (THN), maka dapat disimpulkan bahwa kredit yang bermasalah terkait pada mobil dengan tahun pembuatan lebih muda 2 tahun daripada kredit yang lunas. Hal ini tentu berdampak pada uang muka (DP), angsuran (ANG) dan bunga kredit (BNG), dimana ketiga faktor dalam sampel data kredit yang bermasalah umumnya lebih besar daripada kredit yang lunas. Denda (DEN) yang dibebankan kredit yang lunas tidak diikuti dengan tunggakan (FRE $=0$ ), sedangkan pada kredit yang bermasalah, selain DEN lebih besar, terdapat tunggakan 1-6 kali, dengan rata - rata tunggakan 2,4 kali. Hasil penelitian menunjukkan bahwa data dapat dikatakan reliable karena Cronbach's Alpha $=0.606>0.60$, seperti ditunjukkan pada Tabel 3.

Tabel 3 Uji Reabilitas data

Reliability Statistics

\begin{tabular}{|c|r|}
\hline $\begin{array}{c}\text { Cronbach's } \\
\text { Alpha }\end{array}$ & N of Items \\
\hline 606 & 7 \\
\hline
\end{tabular}

Data dapat dikatakan valid karena Corrected Item Total Corelation (r hitung) lebih besar daripada r table $(0,26)$, seperti ditunjukkan pada Tabel 4 berikut.

Tabel 4 Uji Normalitas Data

\begin{tabular}{|c|c|c|c|c|}
\hline \multicolumn{5}{|c|}{ Item-Total Statistics } \\
\hline & $\begin{array}{l}\text { Scale livean if } \\
\text { ltem Deleted }\end{array}$ & $\begin{array}{c}\text { Scale } \\
\text { Variance if } \\
\text { Iterm Deleted }\end{array}$ & $\begin{array}{l}\text { Corrected } \\
\text { Item-Total } \\
\text { Correlation }\end{array}$ & $\begin{array}{l}\text { Cronbach's } \\
\text { Alpha if Item } \\
\text { Deleted }\end{array}$ \\
\hline OTR & $2.08003963 \mathrm{E} 3$ & 1742.748 & .910 & 610 \\
\hline DP & $2.20407988 \mathrm{E} 3$ & 8365.504 & .716 & 455 \\
\hline ANGSURAN & $2.23090246 \mathrm{E} 3$ & 11510.747 & .916 & 604 \\
\hline DENDA & $2.23023081 E 3$ & 10863.179 & .621 & .575 \\
\hline $\begin{array}{l}\text { FREKUENSI } \\
\text { TUNGOAKANT }\end{array}$ & $2.23417338 \mathrm{E} 3$ & 11881.620 & .048 & 623 \\
\hline BUNGA & $2.20324074 \mathrm{E} 3$ & 9332.578 & .772 & .496 \\
\hline TAHUN_MOBIL & $2.29573380 \mathrm{E} 2$ & 11534.194 & .355 & 607 \\
\hline
\end{tabular}


Dari hasil uji normalitas diatas, dapat disimpulkan bahwa data berdistribusi tidak normal karena memiliki Sig < 0.05. Mengingat data sampel terserbut sangat penting dan tetap akan dimanfaatkan, maka data-data sampel tersebut dikonversikan ke dalam bilangan logaritma normal untuk dilakukan uji normalitas kembali, hal ini lazim dilakukan mengingat keterbatasan data (Keller, 2008).

Hasil analisis ulang data sampel sesudah dikonversi ke logaritma normal menunjukkan hanya variabel Angsuran (ANGS) dan Bunga (BNG) yang termasuk data normal, kedua variabel tersebut diuji ulang secara khusus dengan hasil Cronbach's Alpha $=0.909$ seperti ditunjukkan pada tabel di bawah ini, dengan demikian data sampel sesudah dikonversi ke logaritma normal termasuk realible.

Tabel 5 Uji Ulang Normalitas Data

Reliability Statistics

\begin{tabular}{|c|c|}
\hline Cronbach's Alpha & N of Items \\
\hline .909 & 2 \\
\hline
\end{tabular}

Item-Total Statistics

\begin{tabular}{|c|c|c|c|c|}
\hline & $\begin{array}{c}\text { Scale Mean if Item } \\
\text { Deleted }\end{array}$ & $\begin{array}{c}\text { Scale Variance if Item } \\
\text { Deleted }\end{array}$ & $\begin{array}{c}\text { Corrected Item-Total } \\
\text { Correlation }\end{array}$ & $\begin{array}{c}\text { Cronbach's Alpha if } \\
\text { Item Deleted }\end{array}$ \\
\hline Angsuran & 3.3522 & .250 & .834 & ${ }^{a}$ \\
Bunga & 1.3977 & .218 & .834 & ${ }^{a}$ \\
\hline
\end{tabular}

a. The value is negative due to a negative average covariance among items. This violates reliability model assumptions. You may want to check item codings.

.Case Processing Summary

\begin{tabular}{|c|c|c|c|c|c|c|}
\hline \multirow{2}{*}{} & \multicolumn{2}{|c|}{ Calid } & \multicolumn{2}{c|}{ Missing } & \multicolumn{3}{c|}{ Total } \\
\cline { 2 - 7 } & $\mathbf{N}$ & Percent & $\mathbf{N}$ & Percent & \multicolumn{2}{c|}{ N Percent } \\
\cline { 2 - 7 } & 40 & $100.0 \%$ & 0 & $.0 \%$ & 40 & $100.0 \%$ \\
Angsuran & 40 & $100.0 \%$ & 0 & $.0 \%$ & 40 & $100.0 \%$ \\
\hline
\end{tabular}

Tests of Normality

\begin{tabular}{|c|c|c|c|c|c|c|}
\hline & \multicolumn{3}{|c|}{ Kolmogorov-Smirnov ${ }^{a}$} & \multicolumn{3}{|c|}{ Shapiro-Wilk } \\
\hline & Statistic & df & Sig. & Statistic & df & Sig. \\
\hline Angsuran & .089 & 40 & $.200^{*}$ & .975 & 40 & .502 \\
\hline Bunga & .100 & 40 & $.200^{*}$ & .973 & 40 & .437 \\
\hline
\end{tabular}

a. Lilliefors Significance Correction

*. This is a lower bound of the true significance.

Tabel 5 menunjukkan bahwa variabel Angsuran (ANGS) dan Bunga (BNG) memiliki Sig > 0.05, sehingga kedua variabel dikatakan berdistribusi normal. Tahap analisis selanjutnya menunjutkkan bahwa Multiple $R=0.62$ diartikan bahwa korelasi berganda tersebut termasuk medium dan berhubungan positif antara variabel-variabel bebas dengan variabel terikat. $\mathrm{R}$ Square $=0.388$ menunjukkan 38.8\%perubahan variabel bebas mempengaruhi perubahan variabel terikat. sedangkan sisanya yaitu dijelaskan oleh variasi-variasi lain. 
Tabel 6 Analisis Korelasi Berganda

\begin{tabular}{|l|r|}
\hline \multicolumn{2}{|c|}{ Regression Statistics } \\
\hline Multiple R & 0.6234 \\
\hline R Square & 0.3887 \\
\hline Adjusted R Square & 0.3556 \\
\hline Standard Error & 0.4064 \\
\hline Observations & 40 \\
\hline
\end{tabular}

Standar Error $(\mathrm{SE})=0.40$ menunjukkan variasi sebesar 0.40 disekeliling garis regresi khususnya terhadap variabel terikat. Pada prinsipnya, SE mempunyai pengertian yang sama terhadap standar deviasi dalam statistik deskriptif, karena itu semakin besar SE maka semakin tersebar variable $\mathrm{Y}$ riil dari garis regresinya.

Tabel 7 Analisis signifikan Faktor Regresi Berganda

\begin{tabular}{|l|r|c|c|c|r|}
\hline \multicolumn{7}{|l|}{ ANOVA } & \multicolumn{1}{|c|}{$\boldsymbol{d f}$} & \multicolumn{1}{|c|}{ SS } & MS & $\boldsymbol{F}$ & Significance $\boldsymbol{F}$ \\
\hline & 2 & 3.88707001 & 1.943535005 & 11.76371974 & 0.000111074 \\
\hline Regression & 37 & 6.11292999 & 0.165214324 & & \\
\hline Residual & 10 & & & \\
\hline Total & 39 & 10 & & & \\
\hline
\end{tabular}

F-Hitung $=11,76$ dan F-Tabel $=0$ 0,00011, karena F-Hitung $>$ F-Tabel, maka $\mathrm{H}_{0}$ ditolak, sehingga $\mathrm{H}_{1}$ diterima, dengan demikian variabel Angsuran (ANG) dan bunga (BNG) secara bersama-sama berpengaruh terhadap kredit status kredit dengan tingkat siginifikan 5\%. Hasil ini menjawab tujuan penelitian yang pertama.

Tabel 8 Analisis koefisien Model Regresi Berganda

\begin{tabular}{|l|c|r|c|c|}
\hline & Coefficients & Standard Error & \multicolumn{1}{c|}{ Stat } & P-value \\
\hline Intercept & 3.090341123 & 0.539146751 & 5.731910867 & $1.44885 \mathrm{E}-06$ \\
\hline Angsuran & 0.776333952 & 0.253155671 & 3.066626747 & 0.004032461 \\
\hline Bunga & -1.096203662 & 0.236822883 & -4.628791129 & $4.41326 \mathrm{E}-05$ \\
\hline
\end{tabular}

Berdasarkan tabel di atas, maka persamaan regresi berganda dari model peramalan status kredit dapat dinyatakan sebagai berikut (pembulatan 2 desimal):

$$
\text { Status Kredit }=3.09+\text { 0,77 Lon (Angsuran) }-1,09 \text { Lon (Bunga) }
$$

Hasil di atas sekaligus menjawab tujuan penelitian yang kedua. Selanjutnya, persamaan di atas digunakan untuk menentukan prediksi Status Kredit yang akan dibandingkan dengan data aktualnya, guna menentukan tingkat akurasi model, dengan hasil berikut untuk menentukan tingkat akurasi peramalan model regresi berganda, seperti yang telah disampaikan sebagai tujuan penelitian ketiga. 
Tabel 9 Analisis akurasi Model Regresi Berganda

\begin{tabular}{|c|c|c|c|c|c|c|}
\hline No & Lon(Ang) & Lon(Bng) & $\mathbf{Y}_{\text {Actual }}$ & $\mathbf{Y}_{\text {Pred }}$ & $\mathbf{Y}_{\text {Pred Adj }}$ & Status \\
\hline 1 & 2.13 & 3.92 & 1 & 0.4446 & 0 & - \\
\hline 2 & 0.59 & 2.34 & 1 & 0.98224 & 1 & Correct \\
\hline 3 & 1.32 & 3.01 & 1 & 0.81515 & 1 & Correct \\
\hline 4 & 0.61 & 2.36 & 1 & 0.97778 & 1 & Correct \\
\hline 5 & 1.35 & 3.13 & 1 & 0.70816 & 1 & Correct \\
\hline 6 & 1.29 & 2.98 & 1 & 0.81831 & 1 & Correct \\
\hline 7 & 1.15 & 3.51 & 1 & 0.1331 & 0 & - \\
\hline 8 & 0.79 & 2.59 & 1 & 0.85807 & 1 & Correct \\
\hline 9 & 1.62 & 3.46 & 1 & 0.55721 & 1 & Correct \\
\hline 10 & 1.06 & 3.03 & 1 & 0.59005 & 1 & Correct \\
\hline 11 & 1.81 & 3.19 & 1 & 0.99996 & 1 & Correct \\
\hline 12 & 1.21 & 3.46 & 1 & 0.24118 & 0 & - \\
\hline 13 & 1.32 & 2.94 & 1 & 0.89231 & 1 & Correct \\
\hline 14 & 1.48 & 3.42 & 1 & 0.49033 & 0 & - \\
\hline 15 & 1.56 & 3.54 & 1 & 0.41855 & 0 & - \\
\hline 16 & 1.67 & 3.17 & 1 & 0.91109 & 1 & Correct \\
\hline 17 & 0.92 & 2.63 & 1 & 0.91714 & 1 & Correct \\
\hline 18 & 1.48 & 2.94 & 1 & 1.00992 & 1 & Correct \\
\hline 19 & 1.40 & 3.37 & 1 & 0.48258 & 0 & - \\
\hline 20 & 1.50 & 3.30 & 1 & 0.63933 & 1 & Correct \\
\hline 21 & 1.79 & 3.77 & 0 & 0.34636 & 0 & Correct \\
\hline 22 & 1.95 & 4.07 & 0 & 0.14078 & 0 & Correct \\
\hline 23 & 1.18 & 3.57 & 0 & 0.09129 & 0 & Correct \\
\hline 24 & 1.81 & 3.85 & 0 & 0.27855 & 0 & Correct \\
\hline 25 & 2.12 & 4.28 & 0 & 0.0386 & 0 & Correct \\
\hline 26 & 1.00 & 2.97 & 0 & 0.60861 & 1 & - \\
\hline 27 & 0.75 & 2.94 & 0 & 0.44868 & 0 & Correct \\
\hline 28 & 1.79 & 3.83 & 0 & 0.28404 & 0 & Correct \\
\hline 29 & 1.73 & 3.58 & 0 & 0.5127 & 1 & - \\
\hline 30 & 1.18 & 3.02 & 0 & 0.70265 & 1 & - \\
\hline 31 & 1.79 & 3.83 & 0 & 0.28404 & 0 & Correct \\
\hline 32 & 0.34 & 2.73 & 0 & 0.36029 & 0 & Correct \\
\hline 33 & 1.68 & 3.53 & 0 & 0.51949 & 1 & - \\
\hline 34 & 1.81 & 3.85 & 0 & 0.27855 & 0 & Correct \\
\hline 35 & 1.79 & 3.83 & 0 & 0.28404 & 0 & Correct \\
\hline 36 & 0.49 & 2.74 & 0 & 0.46187 & 0 & Correct \\
\hline 37 & 1.59 & 3.43 & 0 & 0.56369 & 1 & - \\
\hline 38 & 2.32 & 4.26 & 0 & 0.22036 & 0 & Correct \\
\hline 39 & 1.21 & 3.90 & 0 & -0.2413 & 0 & Correct \\
\hline 40 & 1.33 & 3.82 & 0 & -0.0704 & 0 & Correct \\
\hline
\end{tabular}

Hasil perbandingan data prediksi dan data aktual, dimana 20 data yang berasal dari data kredit lunas ternyata hanya terdapat 14 yang diprediksi kredit lunas pula (Correct), dengan rentang hasil prediksi dari 0,55721 sampai 1,0092, sedangkan dari 20 data yang berasal dari kredit macet hanya terdapat 15 yang diprediksi kredit macet pula (Correct) dengan rentang hasil prediksi dari -0,2413 sampai 0,46187 .

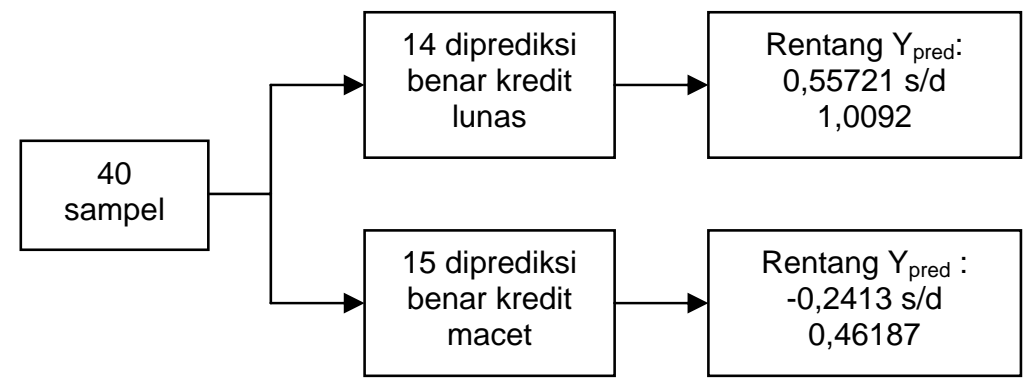

Gambar 1 Bagan analisis akurasi Model Regresi Berganda 
Dengan demikian, 29 dari 40 data diprediksi "Benar" (Correct) atau Error = 11, maka dengan cara yang serupa dengan penentuan tingkat akurasi penelitian Altman (1968), tingkat akurasi model prediksi status kredit pada Astra Credit Companies Cabang X mencapai 72,5\%.

Tabel 10 Rentang kriteria Status Kredit

\begin{tabular}{lc}
\hline \multicolumn{1}{c}{ Area } & Yscore \\
\hline Green (Lunas) & $\geq 0,55721$ \\
Grey (Belum diketahui) & $<0,46187$ sampai $<0,55721$ \\
Red (Kredit Bermasalah) & $\leq 0,46187$ \\
\hline
\end{tabular}

Kedua sampel yang dibedakan (diskriminasi) tersebut terpisah secara jelas, yaitu terdapat rentang data prediksi $\mathrm{Y}_{\text {pred }}$ dari $<0,46187$ sampai $<0,55721$, yang menjadi batas antara kedua sampel tersebut sebagai Grey Area, dengan demikian rentang kriteria Green Area adalah $\geq 0,55721$ dan Red Area adalah <0,46187 sampai <0,55721.

\section{PENUTUP}

Simpulan yang didapat dalam penelitian ini yaitu: (1) hanya terdapat 2 (dua) variabel yang berpengaruh signifikan terhadap Status Kredit dari 7 (tujuh) data mentah yang dianalisis, yaitu Angsuran (ANG) dan Bunga (BNG); (2) hasil analisis regresi berganda diperoleh bahwa model peramalan adalah Status Kredit = 3.09 + 0,77Lon(Angsuran)- 1,09Lon(Bunga); (3) hasil perbandingan antara data aktual dan prediksi status kredit (STS) terdapat 29 dari 40 data yang diprediksi "Benar" (Correct) atau Error = 11, maka tingkat akurasi mencapai 72,5\%.

\section{Saran}

Berdasarkan sensitivitas dari koefisien variabel bebas yang signifikan, maka prioritas pertama yang dimonitor adalah variabel Bunga $\left(\beta_{\text {Bunga }}=1,09\right)$ dan prioritas kedua adalah Angsuran $\left(\beta_{\text {Angsuran }}=\right.$ 0,77). Dengan kata lain, saat analisis kelayakan kredit kendaraan bermotor, penentuan besarnya bunga perlu mempertimbangkan konsep High Return - High Risk, agar perusahaan tidak mengejar laba semata-mata tetapi juga mempertimbangkan potensi risiko kredit bermasalah di masa mendatang. Bidang ilmu Manajemen Portofolio Kredit akan membahas lebih rinci guna meminimalkan pertambahan risiko (risk) sekaligus mengoptimalkan tambahan laba (return). Penelitian ini hanya menggunakan 40 sampel karena keterbatasan data yang diberikan oleh perusahaan, sebaiknya dalam penelitian lanjutan menggunakan sampel yang lebih banyak, agar kualitas model peramalan akan lebih baik. Penelitian lanjutan dapat lebih memanfaat data dari dokumen persyaratan pengajuan kredit, untuk meningkatkan tingkat akurasi model peramalan agar antisipasi kredit bermasalah lebih efektif. 


\section{DAFTAR PUSTAKA}

Altman, E. I. (1968). Financial Ratio, Discriminant Analysis and The Prediction of Corporate Bankruptcy. Journal of Finance, 23(4), 589-609.

Altman, E. I. (2002). Revisiting Credit Scoring Models in a Basel II Environment. Prepared for "Credit Rating: Methodologies, Rationale, and Default Risk”. London Risk Books.

Hardanto, S. S. (2006). Manajemen risiko bagi bank umum: Kisi ujian sertifikasi manajemen risiko perbankan tingkat I. Jakarta: Elex Media Komputindo.

Harmon, M. (2011). Advanced regression in Excel: The complete guide. Excel Master Series.

Judiseno, R. K. (2002). Sistem moneter dan perbankan Indonesia. Jakarta: Gramedia.

Keller, G. (2008). Statistic for management and economics. South-Western Cengage Learning.

Krishnamurthy, P. (2011). Using regression analysis and Altman's multiple discriminat analysis model for estimating receivables. Velammal Engineering College, Anna University, India.

Leech, N. L., Barret, K. C., \& Morgan, G. A. (2005). SPSS for intermediate statistics: Use and interpretation.

Mishkin, F. S. (2008). Buku satu: Ekonomi, uang, perbankan dan pasar keuangan. Salemba Empat.

Rubin, A. (2010). Statistic for evidence-based practice and evaluation. Cengage Learning. 